\title{
Knowledge from Falsehood, Ignorance of Necessary Truths, and Safety
}

\author{
Bin Zhao ${ }^{1}$ ]
}

Received: 24 January 2021 / Revised: 20 June 2021 / Accepted: 26 July 2021 /

Published online: 12 October 2021

(c) The Author(s) 2021

\begin{abstract}
According to the safety account of knowledge, one knows that $p$ only if one's belief could not easily have been false. An important issue for the account is whether we should only examine the target belief when evaluating whether a belief is safe or not. In this paper, it is argued that, if we should only examine the target belief, then the account fails to account for ignorance of necessary truths. But, if we should also examine beliefs in other relevant propositions, then the account fails to account for knowledge from falsehood. Therefore, the safety account of knowledge is undermined by knowledge from falsehood and ignorance of necessary truths.
\end{abstract}

Keywords Epistemic luck · Inference $\cdot$ Knowledge $\cdot$ Knowledge from falsehood Necessary truths $\cdot$ Safety

\section{Introduction}

In many Gettier cases, the target belief is inferred from a false belief. As a result, some epistemologists attempted to solve the Gettier problem by supplementing the JTB analysis of knowledge with a "no-false-lemmas" clause according to which one's belief is not inferred from any falsehood (Armstrong, 1973; Harman, 1973; Lehrer, 1965, 1974; Lycan, 2006). However, the resulting account is too strong ${ }^{1}$ to accommodate cases in which a true belief counts as knowledge despite its being inferred from a false belief. ${ }^{2}$

\footnotetext{
1 It is also too weak to the extent that there are cases in which a justified true belief satisfies the "nofalse-lemmas" clause despite falling short of knowledge. See Feldman (1974).

${ }^{2}$ For arguments that there are no cases of knowledge from falsehood, see Ball and Blome-Tillmann (2014), Borges (2020), Montminy (2014), Schnee (2015). I will consider one such argument in Sect. 4.
}

Bin Zhao

binz8@uci.edu

1 Department of Philosophy, University of California at Irvine, 85 Humanities Instructional Building, Irvine, CA 92697-4555, USA 
The safety account of knowledge produces a welcome result in cases of knowledge from falsehood. The idea behind the account is that in order to know, one's belief could not easily have been false. In short, the belief should be true not only in the actual case, but also in other similar cases (where one forms it in the same way as in the actual case). According to the safety account, a belief that satisfies this condition counts as knowledge unless it exhibits some non-modal shortcomings that would deprive it of the status of knowledge. In a case of knowledge from falsehood, the reason why the true belief counts as knowledge despite its being inferred from a false belief is that the belief in the target proposition, unlike the true belief in a Gettier case, could not easily have been false. ${ }^{3}$

When evaluating whether a belief is safe or not, it was thought that it was enough to examine the belief in the target proposition in similar cases (Sosa, 1999a, b). However, cases where one forms a belief in a necessary truth (or a modally robust contingent truth) calls into question such an account, because such a belief is trivially safe, i.e., the target proposition is true in all possible worlds and, a fortiori, true in all nearby possible worlds where one believes it. Nonetheless, such a belief could still fall short of knowledge despite satisfying other non-modal conditions on knowledge. It was then suggested that we should also take beliefs in other relevant propositions in similar cases into consideration when evaluating whether the belief in the target proposition is safe or not. What results from this suggestion is a globalized version of the safety condition. A belief in a target proposition is globally safe if and only if the subject could not easily have falsely believed not only the target proposition but also the relevant propositions on her actual basis of the belief. This handles the problems incurred by necessary truths nicely: though the subject could not easily have falsely believed the target proposition, the subject could easily have falsely believed some other relevant proposition (Blome-Tillmann, 2017; Grundmann, 2020; Hirvelä, 2019; Manley, 2007; Pritchard, 2009, 2012, 2013, 2016; Williamson, 2000, 2009).

Though the non-globalized safety condition is satisfied in cases of knowledge from falsehood, a remaining issue is whether the globalized safety condition is also satisfied. In this paper, I argue that knowledge from falsehood and ignorance of necessary truths constitute two horns of a dilemma for the safety account of knowledge. If the account is globalized to account for ignorance of necessary truths, then it fails to explain why knowledge from falsehood is possible. But, if the account is not globalized, though it accounts for knowledge from falsehood, it fails to explain why not all beliefs in necessary truths count as knowledge. Therefore, the safety account of knowledge is undermined by knowledge from falsehood and ignorance of necessary truths.

\footnotetext{
${ }^{3}$ A similar point is made by Warfield (2005) where he argues that the belief is not accidentally/luckily true in a case of knowledge from falsehood.
} 


\section{Knowledge from Falsehood and Safety}

\section{Consider a classical Gettier case:}

"Smith and Jones have applied for a particular job. But Smith has been told by the company president that Jones will be hired. Smith combines that testimony with his observational evidence of there being ten coins in Jones's pocket. (He had counted them - an odd but imaginable circumstance.) He infers the belief that whoever will get the job has ten coins in their pocket. For convenience, call that belief $b$. It enjoys a reasonable amount of evidential support-from some testimony, observation, and reasoning. Belief $b$ is also true-yet not in the way Smith was expecting it to be true. For he will get the job, and he has ten coins in his pocket. (Neither of those circumstances was known by Smith.) Does he thereby fail to know that the person who will get the job has ten coins in his pocket? Surely so (thought Gettier): belief $b$ is true and justified-but not knowledge. Hence, JTB is false: this case establishes that being true and justified is not sufficient for being knowledge" (Hetherington, 2011, p. 120). ${ }^{4}$

In this case, Smith has a justified true belief that whoever will get the job has ten coins in their pocket. However, the belief is true as a matter of luck and thus does not count as knowledge. After all, it is true because the dose of bad luck that Jones will not be hired is canceled out by the good luck that Smith will be hired and there are ten coins in his pocket. Given that the belief is inferred from falsehood, i.e., Jones will be hired and there are ten coins in Jones' pocket, a reasonable idea is that, if we supplement the JTB analysis of knowledge with a "no-false-lemmas" clause according to which one's belief is not inferred from any falsehood, then the above case could be handled nicely. After all, the belief is inferred from falsehood and thus does not satisfy the "no-false-lemmas" clause.

The bad news is that there are cases in which a true belief counts as knowledge despite its being inferred from a false belief. To illustrate, consider the following case:

SPEEDOMETER: Angela regularly accepts what the speedometer in her car says at face value. Her present belief, so formed, is that she is driving at $79 \mathrm{mph}$ though she is actually driving at $74 \mathrm{mph}$. The problem is that the speedometer usually does not get the speed right exactly but diverges by a few miles from the true number. The error could be as large as $5 \mathrm{mph}$. Angela sees a posted speed limit of $60 \mathrm{mph}$ and goes on to infer that she is driving above $60 \mathrm{mph}^{5}$

\footnotetext{
${ }^{4}$ The case is originated from Gettier (1963).

5 This case is adapted from Baumann (2014) and Murphy (2017) though for a different purpose. For other cases of knowledge from falsehood, see Arnold (2013), Buford and Cloos (2018), Clark (1963), de Almeida (2017), Feit and Cullison (2011), Fitelson (2010), Hawthorne and Rabinowitz (2017), Hiller (2013), Hilpinen (1988), Klein (2008), Saunders and Champawat (1964), Turri (2012, 2019), Warfield (2005).
} 
Intuitively, Angela's belief that she is driving above $60 \mathrm{mph}$ counts as knowledge though it is inferred from the falsehood that she is driving at $79 \mathrm{mph}$.

This case shows that the no-false-lemmas account is too strong as an account of knowledge. In contrast, the safety account of knowledge handles the case nicely. According to this account, the safety condition is a necessary condition on knowledge that helps to eliminate knowledge-precluding luck. $S$ knows that $p$ only if $S$ 's belief that $p$ is safe, that is, only if $S$ could not easily have falsely believed $p$. To put it formally,

SAFETY: $S$ 's belief that $p$, formed on basis $B$, is safe, if and only if, in all nearby possible worlds where $S$ forms a belief that $p$ on basis $B, p$ is true. ${ }^{6}$

This makes us consider whether $p$ is true in nearby possible worlds where $S$ believes that $p$. If $p$ is false in some of these possible worlds, then $S$ 's belief in $p$ is unsafe. Thus, the belief is luckily true and $S$ does not know that $p$. If $p$ is true in all these possible worlds, then $S$ 's belief in $p$ is safe. Thus, the belief is non-luckily true and $S$ knows that $p$ unless it exhibits some non-modal shortcomings, e.g., the belief is not virtuously formed, that would deprive it of the status of knowledge.

Angela knows that she is driving above $60 \mathrm{mph}$ because the belief is safe. Given that the error of the speedometer is under $5 \mathrm{mph}$, there is no nearby possible world in which she believes so on the same basis, i.e., inference from the belief that she is driving at $79 \mathrm{mph}$, while she is driving under $60 \mathrm{mph}$. Despite its being inferred from falsehood, the belief could not easily have been false!

In sum, beliefs inferred from falsehood do not necessarily fall short of knowledge. The safety account of knowledge, unlike the no-false-lemmas account of knowledge, does a nice job to handle cases of knowledge from falsehood. The insight is that a belief inferred from falsehood could turn out to be safe.

\section{Ignorance of Necessary Truths and Globalized Safety}

We not only form beliefs in contingent truths but also form beliefs in necessary truths, e.g., $2+2=4$, there is an infinite number of prime numbers, water is $\mathrm{H}_{2} \mathrm{O}$, etc. Like beliefs in contingent truths, many beliefs in necessary truth are true as a matter of luck and thus do not count as knowledge. For instance,

\footnotetext{
6 The safety condition is sometimes relativized to the belief-formation methods rather than the basis of beliefs. See Blome-Tillmann (2020) for cases where the two versions of the safety condition come apart. For discussions of the individuation of the basis of beliefs/the belief-formation methods, see Alfano (2009), Becker (2012), Bernecker (2020), Black and Murphy (2007), Bogardus and Marxen (2014), Broncano-Berrocal (2014), and Hirvelä (2019). In this paper, I shall not delve into the issue of how to relativize the condition. Proponents of the safety condition on knowledge include Ball (2016), Beddor and Pavese (2020), Dutant (2010, 2016), Greco (2012), Grundmann (2020), Hirvelä (2017, 2019), Lasonen-Aarnio (2010), Luper (2003, 2006a, b), Luper-Foy (1984), Manley (2007), Peet and Pitcovski (2018), Pritchard (2005, 2007, 2008, 2009, 2012, 2013, 2016), Sainsbury (1997), Sosa (1999a, b, 2003, 2007, 2009), Wedgwood (2020), and Williamson (2000, 2009).
} 
CALCULATOR: "Sam looks at a [broken] calculator which tells him that 131,071 is a prime number, and on this basis Sam comes to believe (truly) that 131,071 is indeed prime" (Roland \& Cogburn, 2011, p. 554).

Since 131,071 is prime is a necessary truth, it is true in all possible worlds and, a fortiori, true in all nearby possible worlds where Sam believes it. This makes his belief trivially safe on SAFETY. However, the belief is true as a matter of luck and thus does not count as knowledge. This causes a problem for SAFETY which is supposed to be a necessary condition on knowledge that helps to eliminate knowledgeprecluding luck. $^{7}$

Though Sam could not easily have formed a false belief in the target proposition, he could easily have formed a false belief in a different proposition. Since the calculator is broken, he may as well believe something like 131,071 is a composite number by using the calculator. The insight is that we should also examine beliefs in other relevant propositions in addition to beliefs in the target proposition when evaluating whether a belief is safe or not. As Duncan Pritchard writes,

"the safety principle, properly understood at any rate, is concerned not with the safety of a belief that $p$ (i.e., the proposition actually believed), but rather with the safety of a relevant doxastic output of a belief-forming process (which, while resulting in a belief that $p$ in the actual world, could result in a belief in a different proposition in a near-by possible world). In this way, possible worlds where this process results in a different doxastic output from that which results in the actual world — such as a belief that $q$ rather than that $p$ - can be relevant to the safety of the belief" (Pritchard, 2016, p. 36).

If SAFETY is globalized to a set of propositions rather than the target proposition, then Sam's belief that 131,071 is a prime number turns out to be unsafe which accounts for why it is true as a matter of luck and thus does not count as knowledge. This seems to be a satisfactory solution to the problem incurred by beliefs in necessary truths. The remaining issue is how to determine which propositions are relevant when evaluating whether a belief is safe. After all, there must be some constraint on which propositions are relevant. Otherwise, a belief can hardly be safe as the subject always could easily have formed a false belief in some proposition.

The safety theorists such as Duncan Pritchard have proposed solutions to how the set of relevant propositions is constrained. According to Pritchard's solution, the set of propositions is constrained by the basis of the belief. We should only consider beliefs that are formed on the same basis while beliefs formed on a different basis

\footnotetext{
7 For similar arguments, see Becker (2007), Blome-Tillmann (2017), Collin (2018), Dietz and Hawthorne (forthcoming), Hales (2016), Levy (2011), Melchior (2017, 2021), Miščević (2007), Zhao (2021, forthcoming). Bernecker (2011), Broncano-Berrocal (2019), Freitag (2014), Greco (2016), Hiller and Neta (2007), Hirvelä (2017, 2019), Kripke (2011), Paterson (2020), Stone (2013), and Zhao (2021) also argue that in addition to necessary truths, modally robust contingent truths, which are true in all nearby possible worlds, incur the same problem for SAFETY.
} 
are irrelevant when evaluating whether the belief in the target proposition is safe. ${ }^{8}$ To put it formally,

GLOBALIZED SAFETY ${ }^{P}: S$ 's belief that $p$, formed on basis $B$, is safe, if and only if, in all nearby possible worlds where $S$ forms a belief on basis $B, S$ 's belief is true (Pritchard, 2009, 2012, 2013, 2016).

GLOBALIZED SAFETY ${ }^{P}$ handles CALCULATOR nicely: though Sam could not easily have formed a false belief that 131,071 is a prime number, he could easily have formed a false belief that 131,071 is a composite number on the same basis as that in the actual case. Therefore, his belief in the target proposition is unsafe and thus does not count as knowledge.

\section{Is Knowledge from Falsehood Globally Safe?}

If, as SAFETY suggests, the safety condition is concerned with the modal profile of a belief in the target proposition, then the safety account successfully explains why SPEEDOMETER is a case of knowledge. However, as GLOBALIZED SAFETY ${ }^{P}$ suggests, the safety condition is concerned with the modal profile of the relevant doxastic output of the belief-forming process. Otherwise, the safety account fails to explain why CALCULATOR is not a case of knowledge.

The remaining issue is whether GLOBALIZED SAFETY ${ }^{P}$ accommodates SPEEDOMETER. In that case, Angela forms the belief that she is driving above $60 \mathrm{mph}$ on the basis of inference from the belief that she is driving at $79 \mathrm{mph}$. Consider a nearby possible world in which Angela is still driving at $74 \mathrm{mph}$ and the speedometer is as reliable as that in the actual world. As a result, the speedometer still indicates $79 \mathrm{mph}$. The only difference is that Angela wonders whether the speed is above $75 \mathrm{mph}$ rather than $60 \mathrm{mph}$. In that world, Angela goes on to infer that she is driving above $75 \mathrm{mph}$. Unlike her actual belief that she is driving above $60 \mathrm{mph}$, this belief is false because she is driving at $74 \mathrm{mph}$. However, the false belief and the actual belief are formed on the same basis, i.e., inference from the belief that she is driving at $79 \mathrm{mph}$. Therefore, GLOBALIZED SAFETY ${ }^{P}$ delivers the incorrect verdict that her actual belief is unsafe and thus does not count as knowledge.

One might respond that, though Angela believes that she is driving at $79 \mathrm{mph}$, she also forms an approximate belief, i.e., she is driving at approximately $79 \mathrm{mph}$, when reading the speedometer and it is the approximate belief that is playing a role in inference while the exact belief is inferentially inert. Thus, the so-called "knowledge from falsehood" should be re-described as knowledge despite falsehood (Ball \& Blome-Tillman, 2014). If she is inferring from the approximate belief rather than the

\footnotetext{
${ }^{8}$ This is motivated by his anti-luck epistemology according to which the safety condition is the anti-luck condition on knowledge. As he argues, when evaluating whether an event is lucky, we should consider nearby possible worlds where the relevant initial conditions for that event are the same as that in the actual world. When the event is the formation of a belief, the relevant initial conditions turn out to be the basis of that belief. See Pritchard (2005, 2007, 2012).
} 
exact belief, then she would be more cautious when making an inference. Though she is willing to infer that she is driving above $60 \mathrm{mph}$, she is reluctant to infer that she is driving above $75 \mathrm{mph}$. In that case, she could not easily have falsely believed that she is driving above $75 \mathrm{mph}$. Therefore, she could not easily have formed a false belief on the same basis and thus her belief that she is driving above $60 \mathrm{mph}$ is safe on GLOBALIZED SAFETY ${ }^{P}$.

In response to the strategy which appeals to the approximate belief, we could fix the case to the extent that Angela has a very strong reason to only form exact beliefs about the speed:

SPEEDOMETER II: Angela regularly has the speedometer in her car calibrated at the best local auto mechanic shop. The staff there always do an excellent job. In fact, Angela uses a reliable radar speedometer to test if the speedometer in the car is accurate several times. The numbers shown on both speedometers always match perfectly. Therefore, Angela regularly accepts what the speedometer in her car says at face value.

One day, after having the speedometer calibrated again in the auto mechanic, she forms the belief that she is driving at $79 \mathrm{mph}$ by reading the speedometer on her way home. However, she is actually driving at $74 \mathrm{mph}$. The problem is that the job was done by an apprentice who is not familiar enough with calibration this time. After the calibration, the speedometer does not get the speed right exactly but diverges by a few miles from the true number. The error could be as large as $5 \mathrm{mph}$. Angela sees a posted speed limit of $60 \mathrm{mph}$ and goes on to infer that she is driving above $60 \mathrm{mph}$.

In this case, by reading the speedometer, Angela only forms an exact but false belief that Angela is driving at $79 \mathrm{mph}$ and infers that Angela is driving above $60 \mathrm{mph}$. Arguably, Angela still knows that Angela is driving above $60 \mathrm{mph}$ as the belief's being true is not a matter of luck. However, as argued above, she could easily have falsely believed Angela is driving above $75 \mathrm{mph}$ on the same basis, i.e., inference from the belief that she is driving at $79 \mathrm{mph}$. Therefore, the problem for GLOBALIZED SAFETY ${ }^{P}$ is still lurking around!

The proponents of the strategy which appeals to the approximate belief might argue that it is psychologically implausible for Angela to only form the exact belief that Angela is driving at $79 \mathrm{mph}$ but not the approximate belief that she is driving at approximately $79 \mathrm{mph}$. Even if we take a step back and grant that it is psychologically implausible to only form exact beliefs, the problem is that the proponents of the strategy still need to demonstrate that it is the approximate belief that is playing a role in inference while the exact belief is inferentially inert. That would be a difficult task to complete.

In addition to cases of knowledge from/despite falsehood, we seem to have lots of cases where knowledge is gained through inference from a true exact belief. If the exact belief is inferentially inert in a case of knowledge from/despite falsehood, then we might wonder whether exact beliefs are always inert in inferences. It could either be the case that, while false exact beliefs are inferentially inert, true exact beliefs are not, or be the case that exact beliefs are always inferentially inert. If the proponents of the strategy take the first horn, then they still owe us an explanation of why 
whether a belief is true or not matters to whether it is inferentially inert or not. If they take the second horn, then the burden of proof to demonstrate that exact beliefs are always inferentially inert is still on them. In either case, it is far from satisfactory to claim that it is psychologically implausible to only form exact beliefs.

\section{Possible Replies}

I shall now briefly discuss two possible replies which are supposed to dissolve the dilemma constituted by knowledge from falsehood and ignorance of necessary truths for the safety theorists.

Timothy Williamson has proposed a different solution to how the set of relevant propositions is constrained. Unlike Pritchard who thinks that we should only consider beliefs that are formed on the same basis when evaluating whether the belief in the target proposition is safe, he argues that a belief in a proposition that is formed on a different basis can also be relevant to whether the belief in the target proposition is safe or not as long as the proposition is close to the target proposition and the basis is also close to the actual basis. To put it formally,

GLOBALIZED SAFETY $^{W}: S$ 's belief that $p$, formed on basis $B$, is safe, if and only if, in all nearby possible worlds where $S$ forms a belief in a proposition close to $p$ on a basis close to $B, S$ 's belief is true (Williamson, 2000, 2009).

Williamson, as a knowledge-first epistemologist, also argues that the safety account of knowledge is unable to settle on what counts as a basis, and what counts as a close proposition, independently of a judgment about whether the subject knows that $p$. According to his knowledge-first epistemology, though safety is a necessary condition on knowledge, we should appeal to the intuition about knowledge to judge whether a belief is safe or not as well as what counts as a basis or a relevantly similar proposition rather than the other way around (Williamson, 2000).

Understood in this way, one might argue that the proposition that she is driving above $75 \mathrm{mph}$ is not close to the proposition that she is driving above $60 \mathrm{mph}$, and thus Angela's belief in the latter is safe; while the proposition that 131,071 is a composite number is close to the proposition that 131,071 is a prime number and thus Sam's belief in the latter is unsafe by appeal to the intuition about knowledge.

To clarify, this paper mainly targets the safety theorists who take safety to be a necessary and non-circular condition on knowledge. In addition, though this paper does not target the safety theorists who take safety to be a necessary and circular condition on knowledge, I think the account is not well-motivated. In order to see why it is safety rather than its competitors, e.g., sensitivity, adherence, virtuous methods of belief-formation, that is necessary for knowledge, a reasonable strategy is to see whether our judgments about safety accommodate intuitions about knowledge. If judgments about safety accommodate intuitions about knowledge while judgments about the competitors of safety fail to do so, then safety is motivated as a necessary condition on knowledge. If, according to knowledge-first epistemology, judgments about safety cannot be made without appeal to intuitions about knowledge, then it is unclear why safety does a better job than its competitors to be motivated as a 
necessary condition for knowledge. In short, the safety account which takes safety to be a necessary and circular condition on knowledge is not as well-motivated as its counterpart which takes safety to be a non-circular condition on knowledge.

This is not to deny the significant role of safety taken as a circular condition on knowledge in epistemology such as unveiling the structural properties of knowledge, figuring in the anti-luminosity argument, and undermining the KK principle (Williamson, 2000). My claim here is less ambitious to the extent that the safety account which takes safety to be a necessary and circular condition on knowledge is not as well-motivated as its counterpart which takes safety to be a non-circular condition on knowledge. Once again, it is the latter that the paper mainly targets.

Hirvelä argues that we should only consider beliefs that are formed on the same virtuous method and propositions which belong to the same subject matter of inquiry as the target proposition. To put it formally,

GLOBALIZED SAFETY ${ }^{H}: S$ 's belief that $p$, which belongs to her subject matter of inquiry $Q$, formed on a virtuous method $V$, is safe, if and only if, in all nearby possible worlds where $S$ forms a belief in a proposition that belongs to $Q$ via the virtuous method $V, S$ 's belief is true (Hirvelä, 2017, 2019).

Like GLOBALIZED SAFETY ${ }^{P}$, GLOBALIZED SAFETY ${ }^{H}$ also handles ignorance of necessary truths such as CALCULATOR nicely. Though Sam could not easily have formed a false belief that 131,071 is a prime number, he could easily have formed a false belief that 131,071 is a composite number on the same virtuous method as that in the actual case. In addition, the true proposition and the false propositions belong to the subject matter of inquiry that "is 131,071 prime or composite?" Therefore, his belief in the target proposition is unsafe and thus does not count as knowledge.

One might wonder if GLOBALIZED SAFETY ${ }^{H}$ does a better job to account for knowledge from falsehood such as SPEEDOMETER. This turns out to be the question of whether Angela's actual belief in the true proposition that she is driving above $60 \mathrm{mph}$ and her counterfactual belief in the false proposition that she is driving above $75 \mathrm{mph}$ belong to the same subject matter of inquiry. As Hirvelä argues, the subject matter of inquiry is partially determined by the practical interests of the subject. We should ask "what is the subject trying to find out?" when individuating the subject matter of inquiry in a given case (Hirvelä, 2019). One might argue that Angela is trying to find out whether she is driving above $60 \mathrm{mph}$ or not. In that case, while both she is driving above $60 \mathrm{mph}$ and she is not driving above $60 \mathrm{mph}$ are potential answers to the question and thus belong to her subject matter of inquiry; she is driving above $75 \mathrm{mph}$ is not a potential answer to the question and thus does not belong to her subject matter of inquiry. Therefore, Angela's counterfactual belief in the false proposition is irrelevant to whether her belief in the target proposition is safe or not. This is a welcome result for GLOBALIZED SAFETY ${ }^{H}$.

\footnotetext{
${ }^{9}$ I thank an anonymous referee for this reply.
} 
The bad news is that GLOBALIZED SAFETY ${ }^{H}$ is too weak to eliminate knowledge-precluding luck if the subject matter of inquiry is individuated by reference to the practical interests of the subject. To illustrate, consider the following case,

MATHEMA: Mathema wonders if $12 \times 13$ is larger than 146 . He uses a calculator to calculate the difference between $12 \times 13$ and 146. The calculator correctly shows that the difference is 10 . As a result, Mathema believes that $12 \times 13$ is larger than 146 since the difference is a positive number. Unbeknownst to Mathema, however, his calculator is in fact broken such that it always generates a positive integer randomly as the "answer."

Presumably, the belief that $12 \times 13$ is larger than 146 is true as a matter of luck and thus does not count as knowledge.

GLOBALIZED SAFETY ${ }^{P}$ handles the case nicely: though Mathema could not easily have formed a false belief that $12 \times 13$ is larger than $146,{ }^{10}$ he could easily have formed a false belief that $12 \times 13-146=20$ on the same basis as that in the actual case. However, this solution is not available to the proponents of GLOBALIZED SAFETY ${ }^{H}$ if the subject matter of inquiry is individuated by reference to the practical interests of the subject. According to this way of individuation, these propositions belong to different subject matters of inquiry: since Mathema is trying to find out whether $12 \times 13$ is larger than 146 rather than the exact difference between them, while the proposition that $12 \times 13$ is larger than 146 belongs to his subject matter of inquiry; the proposition that $12 \times 13-146=20$ does not belong to his subject matter of inquiry. If that is the case, then Mathema's belief in the latter is irrelevant to whether his belief in the former is safe or not. Therefore, GLOBALIZED SAFETY ${ }^{H}$ delivers the incorrect verdict that Mathema's belief that $12 \times 13$ is larger than 146 is safe and thus it is being true is not a matter of luck.

To conclude, in order to accommodate knowledge from falsehood such as SPEEDOMETER, the subject matter of inquiry should be individuated by reference to the practical interests of the subject. However, if the subject matter of inquiry is individuated that way, then GLOBALIZED SAFETY ${ }^{H}$ fails to eliminate knowledgeprecluding luck in some other cases.

\section{Conclusion}

Knowledge from falsehood and ignorance of necessary truths constitute two horns of a dilemma for the safety account of knowledge. On the one hand, knowledge from falsehood requires the safety theorists to focus on the modal profile of the belief in the target proposition. Otherwise, the belief in a case of knowledge from falsehood

\footnotetext{
10 One might argue that Mathema could easily have formed a false belief that $12 \times 13$ is smaller than 146. After all, there are nearby possible worlds where he subtracts $12 \times 13$ from 146 rather than subtracts 146 from $12 \times 13$ while the calculator generates a positive integer as the "answer." Nonetheless, we could fix the case such that Mathema always has a strong inclination to perform multiplication before subtraction. This ensures that he subtracts 146 from $12 \times 13$ rather than the other way around in nearby possible worlds.
} 
would turn out to be unsafe. On the other hand, ignorance of necessary truths requires the safety theorists to focus on the modal profile of the relevant doxastic output of the belief-forming process. Otherwise, beliefs in necessary truths would be trivially safe. Either the safety condition is concerned with the modal profile of the belief in the target proposition or it is concerned with the modal profile of a relevant doxastic output of a belief-forming process but not both. The conclusion is that there is no way that the safety theorists could account for both knowledge from falsehood and ignorance of necessary truths.

Acknowledgements I would like to thank Sven Bernecker, Duncan Pritchard, Karl Schafer, and two anonymous referees for helpful comments and suggestions.

Open Access This article is licensed under a Creative Commons Attribution 4.0 International License, which permits use, sharing, adaptation, distribution and reproduction in any medium or format, as long as you give appropriate credit to the original author(s) and the source, provide a link to the Creative Commons licence, and indicate if changes were made. The images or other third party material in this article are included in the article's Creative Commons licence, unless indicated otherwise in a credit line to the material. If material is not included in the article's Creative Commons licence and your intended use is not permitted by statutory regulation or exceeds the permitted use, you will need to obtain permission directly from the copyright holder. To view a copy of this licence, visit http://creativecommons.org/licen ses/by/4.0/.

\section{References}

Alfano, M. (2009). Sensitivity theory and the individuation of belief-formation methods. Erkenntnis, $60(2), 271-281$.

Armstrong, D. M. (1973). Belief, truth, and knowledge. Cambridge University Press.

Arnold, A. (2013). Some evidence is false. Australasian Journal of Philosophy, 91(1), 165-172.

Ball, B. (2016). Knowledge, safety, and questions. Filosofia Unisinos, 17(1), 58-62.

Ball, B., \& Blome-Tillmann, M. (2014). Counter closure and knowledge despite falsehood. Philosophical Quarterly, 64(257), 552-568.

Baumann, P. (2014). No luck with knowledge? On a dogma of epistemology. Philosophy and Phenomenological Research, 89(3), 523-551.

Becker, K. (2007). Epistemology modalized. Routledge.

Becker, K. (2012). Methods and how to individuate them. In K. Becker \& T. Black (Eds.), The sensitivity principle in epistemology (pp. 81-97). Cambridge University Press.

Beddor, B., \& Pavese, C. (2020). Modal virtue epistemology. Philosophy and Phenomenological Research, 101(1), 61-79.

Bernecker, S. (2011). Keeping track of the Gettier problem. Pacific Philosophical Quarterly, 92(2), $127-152$.

Bernecker, S. (2020). Against global method safety. Synthese, 197(12), 5101-5116.

Black, T., \& Murphy, P. (2007). In defense of sensitivity. Synthese, 154(1), 53-71.

Blome-Tillmann, M. (2017). Sensitivity actually. Philosophy and Phenomenological Research, 94(3), 606-625.

Blome-Tillmann, M. (2020). Non-reductive safety. Belgrade Philosophical Annual, 33, 25-38.

Bogardus, T., \& Marxen, C. (2014). Yes, safety is in danger. Philosophia, 42(2), 1-14.

Borges, R. (2020). Knowledge from knowledge. American Philosophical Quarterly, 57(3), 283-298.

Broncano-Berrocal, F. (2014). Is safety in danger? Philosophia, 42(1), 1-19.

Broncano-Berrocal, F. (2019). Knowledge, safety, and gettierized lottery cases: Why mere statistical evidence is not a (safe) source of knowledge. Philosophical Issues, 29(1), 37-52.

Buford, C., \& Cloos, C. M. (2018). A dilemma for the knowledge despite falsehood strategy. Episteme, 15(2), 166-182.

Clark, M. (1963). Knowledge and grounds: A comment on Mr. Gettier's paper. Analysis, 24(2), 46-48. 
Collin, J. (2018). Towards an account of epistemic luck for necessary truths. Acta Analytica, 33(4), 483-504.

de Almeida, C. (2017). Knowledge, benign falsehoods, and the Gettier problem. In R. Borges, C. de Almeida, \& P. D. Klein (Eds.), Explaining knowledge: New essays on the Gettier problem (pp. 292311). Oxford University Press.

Dietz, C. H., \& Hawthorne, J. (forthcoming). The safety conception of knowledge. In L. Oliveira (Ed.), Externalism About Knowledge. Oxford University Press.

Dutant, J. (2010). Two notions of safety. Swiss Philosophical Preprints, 87, 1-19.

Dutant, J. (2016). How to be an infallibilist. Philosophical Issues, 26(1), 148-171.

Feit, N., \& Cullison, A. (2011). When does falsehood preclude knowledge? Pacific Philosophical Quarterly, 92(3), 283-304.

Feldman, R. (1974). An alleged defect in Gettier counterexamples. Australasian Journal of Philosophy, $52,68-69$.

Fitelson, B. (2010). Strengthening the case for knowledge from falsehood. Analysis, 60(4), 666-669.

Freitag, W. (2014). Safety, sensitivity and 'distant' epistemic luck. Theoria, 80(1), 44-61.

Gettier, E. L. (1963). Is justified true belief knowledge? Analysis, 23(6), 121-123.

Greco, J. (2012). Better safe than sensitive. In K. Becker \& T. Black (Eds.), The sensitivity principle in epistemology (pp. 193-206). Cambridge University Press.

Greco, J. (2016). Knowledge, virtue, and safety. In M. Ángel \& F. Vargas (Eds.), Performance epistemology: Foundations and applications (pp. 51-61). Oxford University Press.

Grundmann, T. (2020). Saving safety from counterexamples. Synthese, 197, 5161-5185.

Hales, S. D. (2016). Why every theory of luck is wrong. Noûs, 50(3), 490-508.

Harman, G. (1973). Thought. Princeton University Press.

Hawthorne, J., \& Rabinowitz, D. (2017). Knowledge and false belief. In R. Borges, C. de Almeida, \& P. D. Klein (Eds.), Explaining knowledge: New essays on the Gettier problem (pp. 325-344). Oxford University Press.

Hetherington, S. (2011). The Gettier problem. In S. Bernecker \& D. Pritchard (Eds.), The Routledge companion to epistemology (pp. 119-131). Routledge.

Hiller, A. (2013). Knowledge essentially based upon false belief. Logos and Episteme, 4(1), 7-19.

Hiller, A., \& Neta, R. (2007). Safety and epistemic luck. Synthese, 158, 303-313.

Hilpinen, R. (1988). Knowledge and conditionals. Philosophical Perspectives, 2, 157-182.

Hirvelä, J. (2017). Is it safe to disagree? Ratio, 30, 305-321.

Hirvelä, J. (2019). Global safety: How to deal with necessary truths. Synthese, 196(3), 1167-1186.

Klein, P. (2008). Useful false beliefs. In Q. Smith (Ed.), Epistemology: New essays (pp. 25-63). Oxford University Press.

Kripke, S. (2011). Nozick on knowledge. Philosophical troubles: Collected papers (Vol. 1, pp. 162-224). Oxford University Press.

Lasonen-Aarnio, M. (2010). Unreasonable knowledge. Philosophical Perspectives, 24(1), 1-21.

Lehrer, K. (1965). Knowledge, truth and evidence. Analysis, 25, 168-175.

Lehrer, K. (1974). Knowledge. Oxford University Press.

Levy, N. (2011). Hard luck: How luck undermines free will and moral responsibility. Oxford University Press.

Luper, S. (2003). Indiscernability skepticism. In S. Luper (Ed.), The skeptics: Contemporary essays (Ashgate epistemology and mind series) (pp. 183-202). Ashgate Publishing.

Luper, S. (2006a). Dretske on knowledge closure. Australasian Journal of Philosophy, 84(3), 379-394.

Luper, S. (2006b). Restorative rigging and the safe indication account. Synthese, 153(1), 161-170.

Luper-Foy, S. (1984). The epistemic predicament: Knowledge, nozickian tracking, and scepticism. Australasian Journal of Philosophy, 62(1), 26-49.

Lycan, W. (2006). On the Gettier problem problem. In S. Hetherington (Ed.), Epistemology futures (pp. 148-168). Clarendon Press.

Manley, D. (2007). Safety, content, apriority, self-knowledge. Journal of Philosophy, 104(8), 403-423.

Melchior, G. (2017). Epistemic luck and logical necessities: Armchair luck revisited. In B. Borstner \& S. Gartner (Eds.), Thought experiments between nature and society: A festschrift for Nenad Miščević (pp. 137-150). Cambridge Scholars Publishing.

Melchior, G. (2021). Sensitivity, safety, and impossible worlds. Philosophical Studies, 178, 713-729.

Miščević, N. (2007). Armchair luck: Apriority, intellection and epistemic luck. Acta Analytica, 22(1), 48-73.

Montminy, M. (2014). Knowledge despite falsehood. Canadian Journal of Philosophy, 44, 463-475. 
Murphy, P. (2017). Justified belief from unjustified belief. Pacific Philosophical Quarterly, 98(4), $602-617$.

Paterson, N. J. (2020). Safety and necessity. Erkenntnis. https://doi.org/10.1007/s10660-020-00231-6

Peet, A., \& Pitcovski, E. (2018). Normal knowledge: Toward an explanation-based theory of knowledge. Journal of Philosophy, 115(3), 141-157.

Pritchard, D. (2005). Epistemic luck. Oxford University Press.

Pritchard, D. (2007). Anti-luck epistemology. Synthese, 158, 277-298.

Pritchard, D. (2008). Knowledge, luck, and lotteries. In V. F. Hendricks \& D. Pritchard (Eds.), New waves in epistemology (pp. 28-51). Palgrave Macmillan.

Pritchard, D. (2009). Safety-based epistemology: Whither now? Journal of Philosophical Research, 34, 33-45.

Pritchard, D. (2012). Anti-luck virtue epistemology. Journal of Philosophy, 109(3), 247-279.

Pritchard, D. (2013). Knowledge cannot be lucky. In M. Steup, J. Turri, \& E. Sosa (Eds.), Contemporary debates in epistemology (2nd ed., pp. 152-164). Blackwell.

Pritchard, D. (2016). Epistemology (2nd ed.). Palgrave Macmillan.

Roland, J., \& Cogburn, J. (2011). Anti-luck epistemologies and necessary truths. Philosophia, 39(3), 547-561.

Sainsbury, R. M. (1997). Easy possibilities. Philosophy and Phenomenological Research, 57(4), 907-919.

Saunders, J. T., \& Champawat, N. (1964). Mr. Clark's definition of 'knowledge.' Analysis, 25(1), 8-9.

Schnee, I. (2015). There is no knowledge from falsehood. Episteme, 12, 53-74.

Sosa, E. (1999a). How must knowledge be modally related to what is known? Philosophical Topics, $26(1$ \& 2), 373-384.

Sosa, E. (1999b). How to defeat opposition to moore. Philosophical Perspectives, 13, 141-154.

Sosa, E. (2003). Neither contextualism nor skepticism. In S. Luper (Ed.), The skeptics: Contemporary essays (Ashgate epistemology and mind series) (pp. 165-182). Ashgate Publishing.

Sosa, E. (2007). A virtue epistemology: Apt belief and reflective knowledge (Vol. I). Oxford University Press.

Sosa, E. (2009). Reflective knowledge: Apt belief and reflective knowledge (Vol. II). Oxford University Press.

Stone, J. (2013). ‘Unlucky' Gettier cases. Pacific Philosophical Quarterly, 94(3), 421-430.

Turri, J. (2012). In Gettier's wake. In S. Hetherington (Ed.), Epistemology: The key thinkers (pp. 214229). Continuum.

Turri, J. (2019). Knowledge from falsehood: An experimental study. Thought: A Journal of Philosophy, $8(3), 167-178$.

Warfield, T. A. (2005). Knowledge from falsehood. Philosophical Perspectives, 19(1), 405-416.

Wedgwood, R. (2020). The internalist virtue theory of knowledge. Synthese, 197, 5357-5378.

Williamson, T. (2000). Knowledge and its limits. Oxford University Press.

Williamson, T. (2009). Reply to John Hawthorne and Maria Lasonen-Aarnio. In P. Greenough \& D. Pritchard (Eds.), Williamson on knowledge (pp. 313-329). Oxford University Press.

Zhao, B. (2021). A dilemma for globalized safety. Acta Analytica. https://doi.org/10.1007/s12136-021-00478-w.

Zhao, B. (forthcoming). Epistemic closure, necessary truths, and safety. American Philosophical Quarterly.

Publisher's Note Springer Nature remains neutral with regard to jurisdictional claims in published maps and institutional affiliations. 